\title{
砕波帯外に誘起される渦列
}

\section{A ROW OF VORTICES IN AN OFFSHORE ZONE}

\author{
松永信博*.粟谷陽一**. 竹原幸生*** \\ By Nobuhiro MATSUNAGA, Yoichi AWAYA and Kosei TAKEHARA
}

\begin{abstract}
It has been found experimentally that a row of two-dimensional vortices forms in an offshore zone when surface waves climb up a sloping flat bed. The vortices occur near the separation point of the Stokes layer, i. e., near the breaking point, and are transported in the offshore direction. Performing the vortex pairing, the vortices increase their length scales offshorewards. They are nearly equal to the local depth of water. In the case when the slope of the bed from the horizontal is $2.44^{\circ}$, the row of vortices appears when $h_{b} / L_{b} \leqq 0.096$. Here, $h_{b}$ and $L_{b}$ are the mean water depth and the wavelength at the breaking point, respectively.

Keywords: nearshore currents, vortical motion, shear instability
\end{abstract}

\section{1. 緒言}

沿岸域における底質の浮遊・運搬機構を解明するた め, 最近では砕波帯内の定常流や乱れの特性が，実験的 に活発に調べられている．著者の 1 人は，海浜に入射し てきた波が砕波する直前に底質がかなり浮遊することを 見出し，この底質の巻き上がり機構について実験的研究 を行っだ1).その結果，砕波帯付近では波動による岸向 き定常流れと強いリターン・フローとが衝突するため, 砕波直前で振動境界層が剝離し, バックウォッシュ・ボ ルテックス ${ }^{21,3)}$ が形成され，底質がその渦によって巻き 上げられることが明らかとなった.さらに，砕波点から 沖に向かって水面に沿って移流する渦列が誘起されるこ とも指摘された。

本論文では，この渦列の定性的特性とその発生条件を 可視化手法を用いて明らかにする.

\section{2. 実験装置および実験方法}

実験には，全面透明アクリル板で作られた長さ $12 \mathrm{~m}$,

\footnotetext{
* 正会員 工博 九州大学助手 工学部水工土木学科 ( ₹812 福岡市東区箱崎 6-10-1)

** 正会員 工博 九州大学教授 工学部水工土木学科(同上)

*** 学生会員 九州大学工学研究科修士課程 (同上)
}

深さ $0.4 \mathrm{~m}$, 幅 $0.15 \mathrm{~m}$ の水槽を用いた. 水槽の一端には, フラッタ一・タイプの造波機を取り付けた。造波板の振 動周期 $T$ は, 0.5 秒から 2.6 秒まで自由に変えること ができた。水槽の他端に設置した斜板の長さは $8.5 \mathrm{~m}$ あり, 斜板の沖側の端から岸側 $2.6 \mathrm{~m}$ の地点を A点と し，岸方向に $0.5 \mathrm{~m}$ の間隔で $\mathrm{B}, \mathrm{C}, \mathrm{D}, \cdots$ と記号を付け た. 今回の実験では, 斜板の勾配 $\theta$ を $2.44^{\circ}$ に固定した.

水平床における平均水深は, $27.0 \mathrm{~cm}$ から $31.0 \mathrm{~cm}$ の 間で変えられた。砕波形態は spilling 型から plunging 型，そして surging 型にわたる広範囲で実験を行った。 波動場が，ほぼ定常状態に達した後，流れを可視化する ためのトレーサーとしてアニリン・ブルー粒子を水表面 に散布することによって，砕波帯外の流れのパターンを 観察した。流れのパターンは，水槽に対して固定された $35 \mathrm{~mm}$ カメラを用いて撮影された. すべての写真にお いて左側が岸である。

渦列の形成条件を明らかにするため, 砕波点における 波高 $H_{b}$, 波長 $L_{b}$, 平均水深 $h_{b}$ を測定した．波高は，1 本の容量式波高計を砕波点に設置することによって測定 された。 また，波長は 2 本の波高計を既知の間隔で砕波 点付近に設置し, 出力をペン・レコーダに出力させ, 水 面変化の位相差により算定された．砕波点における平均 水深としては,静止状態におけるその点の水深を用いた. 


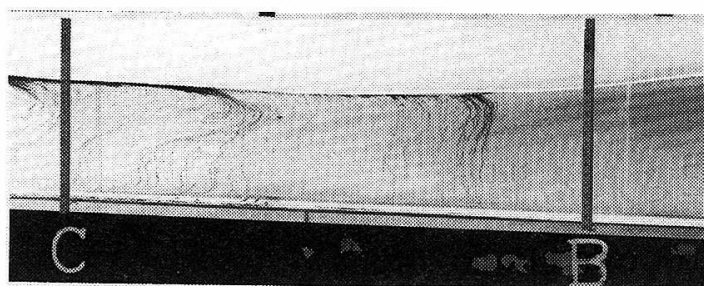

(a)

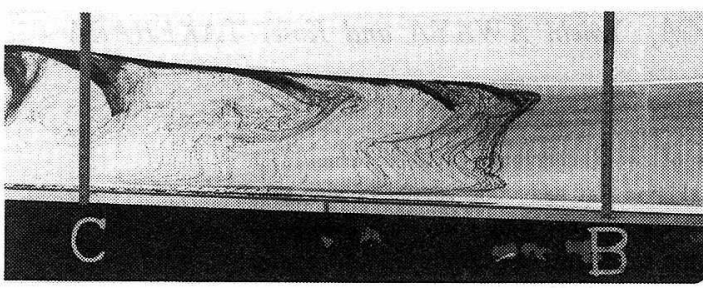

(b)

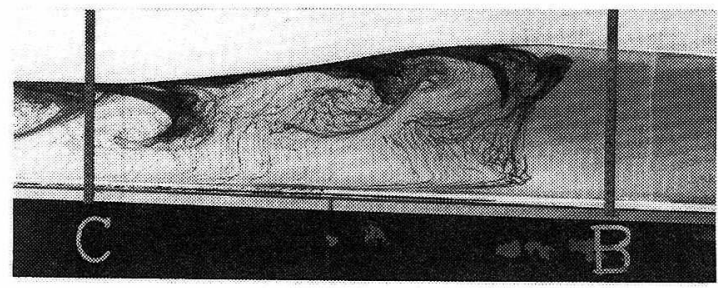

(c)

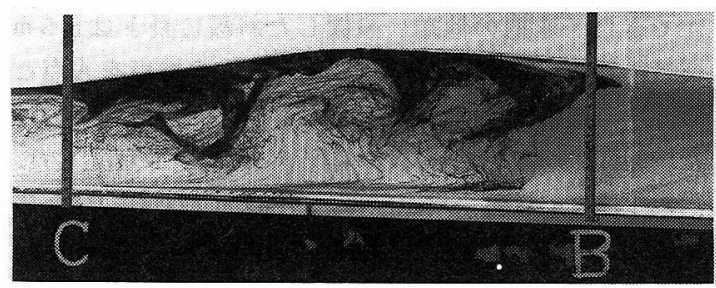

(d)

写真一1 渦列の形成過程

$\left[\begin{array}{l}\text { (a ) }: t=3 \text { 秒, ( ( ) ) }: t=27 \text { 秒 } \\ \text { (c) }: t=43 \text { 秒, ( ( ) ): } t=60 \text { 秒 }\end{array}\right]$

なお，渦列の動態を写真撮影した実験においては $T=$ 1.06 秒であり, 砕波点での特性量は $H_{b}=5.6 \mathrm{~cm}, L_{b}=$ $89 \mathrm{~cm}, h_{b}=5.0 \mathrm{~cm}$ であった.

\section{3. 実験結果および考察}

写真一1(a) から（d）は，水表面に散布されたトレー サーが沈降し, 形成したある種の夕イム・ラインが変形 する過程を示したものである. $t$ は, トレーサー散布後

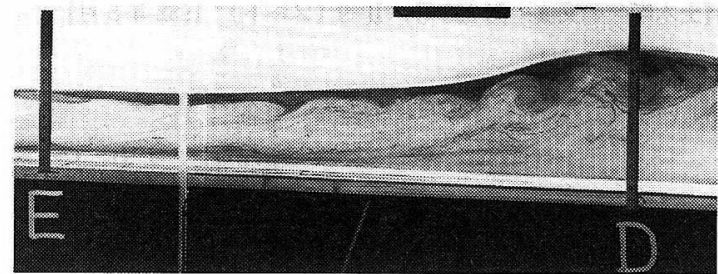

(a)

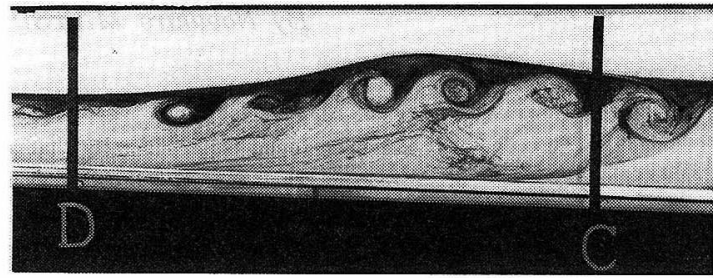

( b )

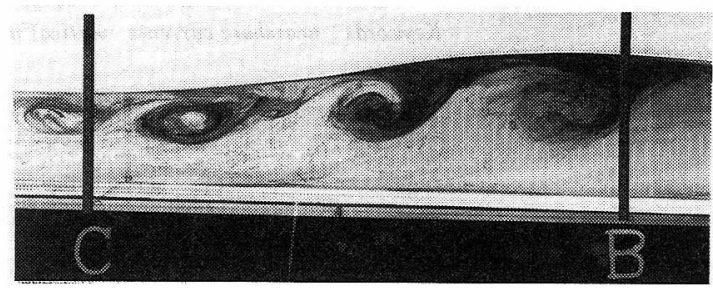

(c)

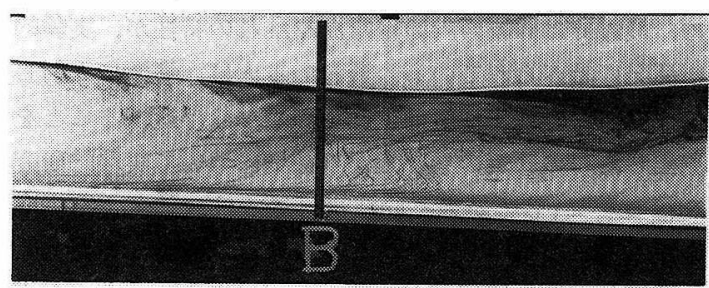

(d)

写真-2 渦列の流下方向のパターン

の経過時間を示す. 写真一1(a) は, $t=3$ 秒におけるパ ターンで, 底面近傍では岸向きの定常流が，水表面付近 はをれを補う沖向きの流れが形成されていることがわか る. 写真一1(b) では夕イム・ラインがかなりゆがめら れ, 前述した定常流の様子が明瞭となっている. 写真一 $1(\mathrm{c})$ ではタイム・ラインはさらに変形し, 渦列の形成 が認められる. 写真一1(d) で示されるように， $t=60$ 秒においてタイム・ラインは渦列の形成を明瞭に示して 


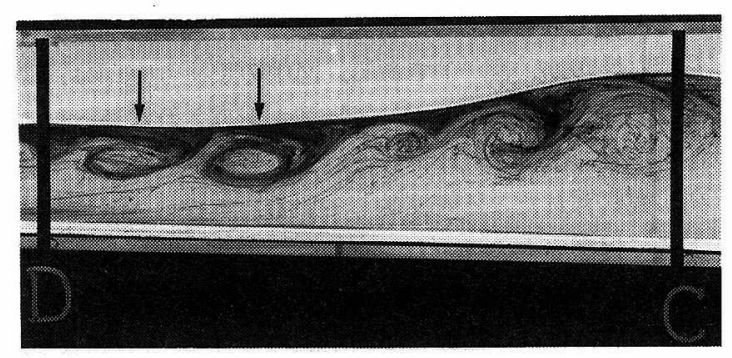

(a)

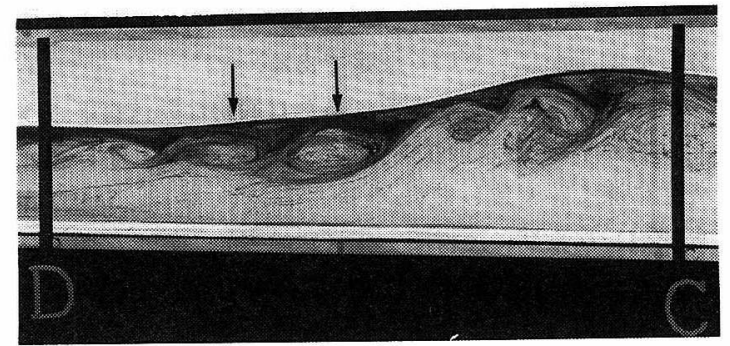

(b)

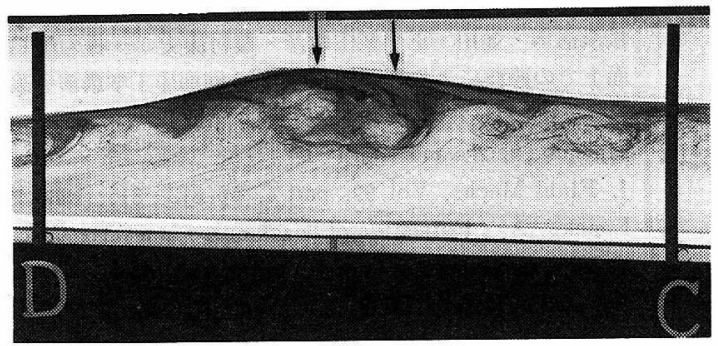

(c)

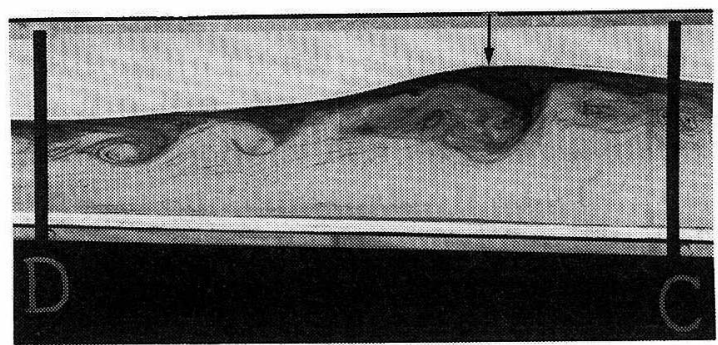

(d)

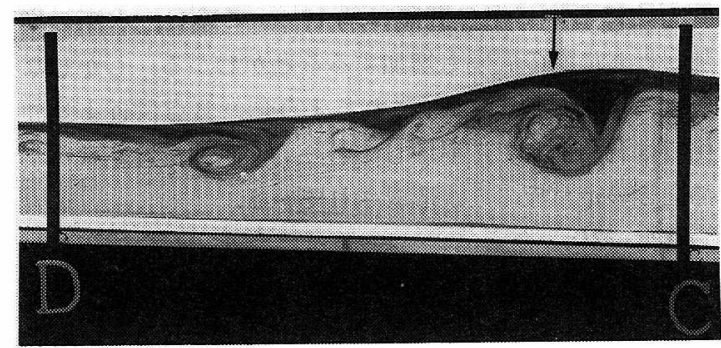

(e)

\section{写真一3 渦と渦との合体過程}

$\left[\begin{array}{l}\text { (a ) }: t=0 \text { 秒, (d ) }: t=50 \text { 秒 } \\ \text { (b ) }: t=11 \text { 秒, ( e ) }: t=65 \text { 秒 } \\ \text { (c) }: t=27 \text { 秒 }\end{array}\right]$

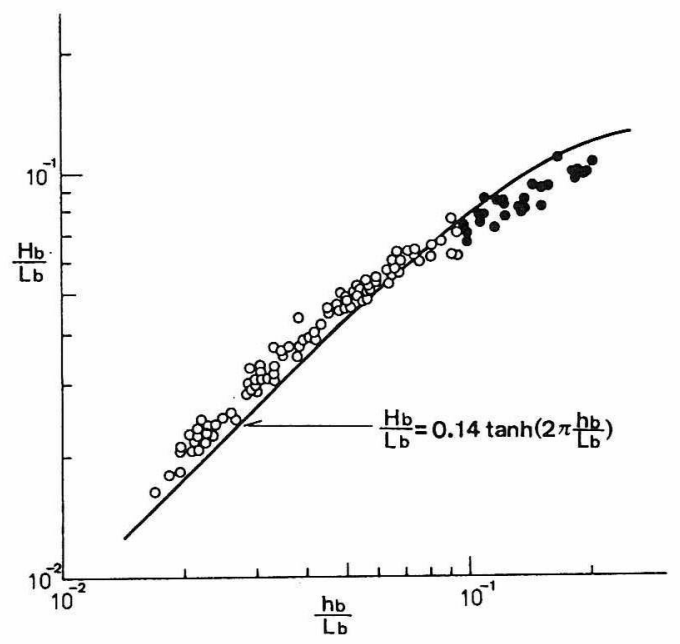

図一1渦列の発生条件 
いる.

写真一2(a) から（d）は，砕波点より沖側における 渦列のパターンを示したものである. $\mathrm{E}, \mathrm{D}, \mathrm{C}, \mathrm{B}$ 点に おける水深はそれぞれ 7.9, 10, $12,14 \mathrm{~cm}$ であり, 砕波 点は E点よりも岸側 $0.68 \mathrm{~m}$ のところであった．写真一 2(a) で示されるように，区間 ED ではトレーサーが波 打ち始めており，定常流が不安定になり始めていること がわかる.トレーサーが示す波状パターンの波長は約 $7.0 \mathrm{~cm}$ である。澗 DC では明瞭な渦列が形成されて いる. DC 間における渦の間隔は約 $9.0 \mathrm{~cm}$ である. 区 間 $\mathrm{CB}$ において渦の間隔は約 $16 \mathrm{~cm}$ に達し，水深の増 加とともに渦の間隔も増加することがわかる．しかしな がら, 写真一2(d) で示されるように，B点付近より沖 側では渦列はすでに崩壊しており，水表面付近ではただ 沖向きの定常流のみが形成されている.

写真一3(a) から（e）は，形成された渦が合体しなが ら渦の間隔を増加させ, 沖に向かって移流していく様子 を示したものである.ここで， $t$ は写真一3(a) が撮影 された後の経過時間である. 写真一3(a) において矢印

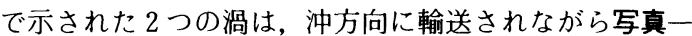
3(b)，(c) で示されるように互いに接近し，そして写真 -3(d), (e) においては前方の渦が後方の渦を連行吸収 する過程が明瞭に観察される.

これまで可視化された流れのパターンに基づいて砕波 点より沖側で形成される渦列に関する定性的特徵をまと めると次のとおりである. Bagnold ${ }^{4)}$ や LonguetHiggins $^{5)}$ らによって明らかにされた底面近傍での岸向 き定常流と, それを補う水表面付近に生じる沖向き定常 流との間のせん断不安定によって発生した渦は，互いに 合体を行いながら，そしてその間隔を水深程度に保ちな がら沖向き流れに乗って輸送される．そして，渦は定常 流のせん断率が減少するところで崩壊するようである.

この渦列は，砕波点付近で形成し始めることがすでに 報告されている1!．したがって，渦列の発生条件は砕波 点における特性量 $H_{b}, L_{b}, h_{b}$ とかなり密接に関係して
いると考えられる. この考えに基づいて渦列の発生条件 を示したのが，図一1である，図中の黒塗り丸印は，砕 波点の沖側全領域にわたって渦列が形成されなかったこ とを示し，白抜き丸印は砕波点よりも沖側のどこかで渦 列が観察されたことを意味している．実線は $\mathrm{Mich}^{6)}$ に よって提案された $h_{b} / L_{b}$ と $H_{b} / L_{b}$ との関係である. 測 定結果は Miche の関係式とわずかに異なっているが, 両者の間にはほぼ類似の傾向が認められる.この図より, 渦列は $\theta=2.44^{\circ}$ の場合 $h_{b} / L_{b} \leqq 0.096$ において発生す ることがわかる. 今後, 渦の長さスケールや移流速度に 関する定量化ならびに，これら特性量の $\theta$ に関する依 存性を明らかにしていく予定である.

最後に, 本研究を進めるにあたり適切な助言を下さっ た九州大学教授 本地弘之先生ならびに助教授 小松利光 先生に深く感謝致します.実験において, 並川 正氏 (鹿 島建設）ならびに榎村康史氏（建設省）の多大な助力を 得たことを感謝致します．また，本研究を行うにあたつ て，服部報公会の工学研究奖励援助を受けたことを付記 する。

1）松永信博・並川 正・柴田敏彦・榎村康史：一様勾配斜 面上での砕波による乱れ特性, 第 33 回海岸工学講演会論 文集, pp. 21 25, 1986.

2) Matsunaga, N. and Honji, H. : The backwash vortex, J. Fluid Mech., Vol. 99, part 4, pp. 813 815, 1980.

3) Kaneko, A. : Formation of beach cusps in a wave tank, Coastal Engineering, Vol.9, pp. 81 98, 1985.

4) Bagnold, R.A. : Sand movement by waves: Some small-scale experiment with sand of very low density, J. Institution Civil Engineers, Vol.27, pp. 447 469, 1947.

5) Longuet-Higgins, M.S. : Mass transport in water waves, Phil. Trans. Roy. Soc. (London), Series A, Vol. 245, No. 903, pp. 535 581, 1953.

6) Miche, R. : Mouvements ondulatories de la mer, Annale Ponts et Chausses, Vol. 114, pp. 25 78, 1944.

(1987.9.22 • 受付) 